\title{
Technology in Caring for Traumatic Brain Injury: Does What Make Sense Really Do?
}

Severe traumatic brain injury is a critical condition carrying a significant burden including a high mortality ${ }^{1}$ and, among an important proportion of survivors, a significant alteration of their quality of life. Over the last decades, the care of patients with severe traumatic brain injury has progressively evolved into a more standardized approach with the development of the management guidelines by the Brain Trauma Foundation. ${ }^{2}$ These guidelines propose a structured approach of care mainly focusing on therapies and management of intracranial pressure control, and are now globally followed by the majority of level I trauma centers. Thus, most research efforts worldwide have been focusing on finding a bullet therapy that could improve clinically significant outcomes by preventing an increase in intracranial pressure and by maintaining cerebral perfusion pressure within a presumably unharmful range. Miscellaneous therapies such as therapeutic hypothermia ${ }^{3,4}$, decompressive craniectomy ${ }^{5}$ or hypertonic saline ${ }^{6}$ have been evaluated in large multicenter randomized control trials. Despite the underlying sound hypotheses, none of these therapies have shown a clear beneficial effect in improving clinically relevant outcomes.

The systematic review by Mendelson and colleagues ${ }^{7}$ published in this issue of the Canadian Journal of Neurological Sciences was designed to evaluate the association between intracranial pressure monitoring and mortality in patients with traumatic brain injury. The authors identified six large observational retrospective cohort studies using multivariable logistic regression to adjust for covariates and confounding factors. The important differences in study design and methodology precluded performing a meta-analysis. Interestingly, one study observed a survival benefit with the use of intracranial pressure monitoring ${ }^{8}$, two studies observed an increased in mortality ${ }^{9,10}$ and three studies observed no survival benefit ${ }^{11-13}$. However, none of these three studies simultaneously adjusted for the three strongest predictors of death in this patient population (age, GCS and pupillary reactivity $)^{14,15}$, although one study controlled for GCS and pupillary reactivity and indirectly controlled for age with the Charlson index ${ }^{11}$. Because an indication bias is highly probable since the use of intracranial pressure monitoring was not randomly distributed, the comparison of groups exposed or not exposed to the intervention must be adjusted for the most important prognostic indicators. In their systematic review, the authors observed that intracranial pressure monitoring was inserted in younger patients with higher injury severity scores, more hypotension and a lower GCS. Not surprisingly, monitored patients were given more aggressive therapy to control intracranial pressure, more invasive procedures and had a longer stay in the intensive care unit. Considering the strength of the association between the prognostic variables with both the decision to use intracranial pressure monitoring and mortality, establishing unbiased causality links is very difficult in presence of non-optimal risk adjustment.

The findings reported by Mendelson and colleagues do not reinforce clinicians on the place of intracranial pressure monitoring should have in the management of severe traumatic brain injury. However, putting into context the weak level of evidence on the cornerstone of monitoring on which most interventions for the management of patients with severe traumatic brain injury are based from, is very important. It highlights not only how we currently practice in a broad grey zone, but also how the technology may sometimes be disseminated and becoming a standard of care practice without having been optimally evaluated.

Physicians caring for patients with severe traumatic brain injury have an important role in ensuring that evidence-based practices are implemented, starting with a thorough evaluation of new technologies before they are part of the care bundle as a standard practice. Recent advances in brain monitoring such as brain tissue $\mathrm{pO}_{2}$ and brain microdialysis are examples of innovative technologies that may play an important role in the management of patients with severe traumatic brain injury in the future. ${ }^{16}$ However, despite that some experts mandate for their immediate utilization, we must at first better understand their added prognostic value, understand whether these parameters are modifiable or not, and if so, whether their modification affects relevant outcomes or not. Thereafter, goal-directed therapy based on data obtained from these invasive devices must be rigorously evaluated in regards to clinically significant outcomes. While the absence of evidence of effect does not mean the evidence of no effect, the corollary is also true: the absence of evidence for harm, does not mean the absence of harm. Considering the long historical perspective and its broad implementation as a standard of care practice, intracranial pressure monitoring as part of the management of patients with severe traumatic brain injury can now hardly be challenged. Then, we must avoid repeating the errors of the past and make sure that new technology will follow a thorough evaluation before widespread dissemination. The burden of proof must rest on the shoulders of clinical research.

Alexis F. Turgeon, François Lauzier Québec City, Québec, Canada Email: alexis.turgeon@fmed.ulaval.ca 


\section{REFERENCES}

1. Turgeon AF, Lauzier F, Simard JF, et al. Mortality associated with withdrawal of life-sustaining therapy for patients with severe traumatic brain injury: a Canadian multicentre cohort study. CMAJ. 2011 Oct 4;183(14):1581-8.

2. Brain Trauma Foundation, American Association of Neurological Surgeons, Joint section on neurotrauma and critical care. Guidelines for the management of patients with severe TBI. J Neurotrauma. 2007; 24: Supp 1.

3. Clifton GL, Valadka A, Zygun D, et al. Very early hypothermia induction in patients with severe brain injury (the National Acute Brain Injury Study: Hypothermia II): a randomised trial. Lancet Neurol. 2011 Feb;10(2):131-9. Epub 2010 Dec 17.

4. Hutchison JS, Ward RE, Lacroix J, et al. Hypothermia Pediatric Head Injury Trial Investigators and the Canadian Critical Care Trials Group. Hypothermia therapy after traumatic brain injury in children. N Engl J Med. 2008 Jun 5;358(23):2447-56.

5. Cooper DJ, Rosenfeld JV, Murray L, et al; DECRA Trial Investigators; Australian and New Zealand Intensive Care Society Clinical Trials Group. Decompressive craniectomy in diffuse traumatic brain injury. N Engl J Med. 2011 Apr 21;364 (16):1493-502. Epub 2011 Mar 25.

6. Cooper DJ, Myles PS, McDermott FT, et al; HTS Study Investigators. Prehospital hypertonic saline resuscitation of patients with hypotension and severe traumatic brain injury: a randomized controlled trial. JAMA. 2004 Mar 17;291(11): 1350-7.

7. Mendelson AA, Gillis G, Henderson WR, Ronco JJ, Dhingra V, Griesdale DEG. Intracranial pressure monitors in traumatic brain injury: a systematic review. Can J Neurol Sci. 2012;39(5):571-6.
8. Shafi S, Diaz-Arrastia R, Madden C, Gentilello L. Intracranial pressure monitoring in brain-injured patients is associated with worsening of survival. J Trauma. 2008 Feb;64(2):335-40.

9. Lane PL, Skoretz TG, Doig G, Girotti MJ. Intracranial pressure monitoring and outcomes after traumatic brain injury. Can J Surg. 2000 Dec;43(6):442-8.

10. Griesdale DE, McEwen J, Kurth T, Chittock DR. External ventricular drains and mortality in patients with severe traumatic brain injury. Can J Neurol Sci. 2010 Jan;37(1):43-8.

11. Thompson HJ, Rivara FP, Jurkovich GJ, Wang J, Nathens AB, MacKenzie EJ. Evaluation of the effect of intensity of care on mortality after traumatic brain injury. Crit Care Med. 2008 Jan; 36(1):282-90

12. Mauritz W, Janciak I, Wilbacher I, Rusnak M; Australian Severe TBI Study Investigators. Severe traumatic brain injury in Austria IV: intensive care management. Wien Klin Wochenschr. 2007 Feb;119(1-2):46-55.

13. Mauritz W, Steltzer H, Bauer P, Dolanski-Aghamanoukjan L, Metnitz P. Monitoring of intracranial pressure in patients with severe traumatic brain injury: an Austrian prospective multicenter study. Intensive Care Med. 2008 Jul;34(7):1208-15. Epub 2008 Mar 26.

14. Perel P, Edwards P, Wentz R, Roberts I. Systematic review of prognostic models in traumatic brain injury. BMC Med Inform Decis Mak. 2006; 6(38): Review.

15. MRC CRASH Trial Collaborators, Perel P, Arango M, Clayton T, et al. Predicting outcome after traumatic brain injury: practical prognostic models based on large cohort of international patients. BMJ. 2008;336(7641):425-9.

16. Hemphill JC, Andrews P, De Georgia M; Medscape. Multimodal monitoring and neurocritical care bioinformatics. Nat Rev Neurol. 2011 Jul 12;7(8):451-60. 